\title{
BOTICA JESUÍTA: APONTAMENTOS SOBRE A PRODUÇÃO DE MEDICAMENTOS E A UTILIZAÇÃO DE RECURSOS NATURAIS NO BRASIL COLONIAL
}

JESUIT PHARMACIES: NOTES ON THE PRODUCTION OF DRUGS AND THE USE OF NATURAL RESOURCES IN COLONIAL BRAZIL

Nadja Paraense Santos* nadja@iq.ufrj.br

Viviane Machado Caminha São Bento** vivianecaminha@gmail.com

RESUMO: Historicizar as diversas práticas médicas e doenças ao longo na trajetória das sociedades humanas requer, para o caso da Época Moderna, evocar a atuação dos jesuítas no que toca ao desenvolvimento dos serviços de saúde. Presentes na América portuguesa desde 1549, os inacianos não se restringiram à prática missionária ou educacional. Em inúmeras situações estabeleceram relações profundas com a população nativa e o conhecimento sobre o mundo natural, aplicando-o no receituário de medicamentos desenvolvidos em suas boticas. A partir disso, nosso objetivo é refletir sobre sua contribuição no desenvolvimento de conhecimentos e processos de cura, enfatizando seu desempenho como fundamental para o viver na colônia.

PALAVRAS-CHAVE: Boticas jesuítas, medicina, América portuguesa

ABSTRACT: Historicizing the various medical practices and disease over the course of human societies requires, in the case of the Modern Era, evoke the work of the Jesuits in relation to the development of health services. In the Portuguese America since 1549, Ignatian not restricted to missionary or educational practice. In many situations established deep relations with the native population and the knowledge of the natural world, applying it in the prescription of drugs developed in their pharmacies. From this, our goal is to reflect on their contribution to the development of knowledge and healing processes, emphasizing their performance as fundamental to live in the colony.

KEYWORDS: Pharmacies jesuits, medicine, Portuguese America

\footnotetext{
* Doutorado em Engenharia de Produção Área de História das Ciências pela COPPE/UFRJ (2002). Professor Adjunto da Universidade Federal do Rio de Janeiro no Programa de Pós-graduação em História das Ciências, das Técnicas e Epistemologia (HCTE) e no Mestrado Profissional de Ensino de Química do Instituto de Química/UFRJ.

${ }^{* *}$ Doutoranda no Programa de Pós-Graduação em História das Ciências, das Técnicas e Epistemologia (HCTE) da Universidade Federal do Rio de Janeiro - UFRJ
} 


\section{Introdução}

O objetivo desse artigo é o de suscitar a reflexão sobre a contribuição da Companhia de Jesus para o desenvolvimento de conhecimentos e processos de cura, a partir de processos de confecção de medicamentos, nas boticas, vinculadas aos Colégios inacianos, espalhados pela América portuguesa. $E$, com isso, sublinhar sua contribuição para a medicina Moderna, bem com o papel desempenhado de médicos de almas e corpos na colônia.

A Companhia de Jesus nasceu como realizadora do projeto missionário e catequético tornando-se a mais viva intérprete da ideia de Cristianismo proposta pela Contra Reforma, caracterizada como movimento que nasceu das crises sociais e da renovação da piedade cristã, originadas em fins do século XIV e início do século XV. (MULLET, 1985, p. 10) Nesse sentido, a Companhia de Jesus se pautou em uma nova interpretação do Cristianismo, inaugurando novas práticas e formas de se relacionar com o mundo e entre os próprios indivíduos.

Com o propósito de levar a fé católica para o mundo, a Companhia se tornou um dos importantes instrumentos da renovação católica. Sua especificidade se centrou no desprendimento, caracterizado na predisposição ao movimento e na obrigação de se envolver com o mundano, ou seja, em estar no mundo, percorrendo-o e indo ao encontro de cristãos desviantes e/ou daqueles que não tinham conhecimento de Deus.

Reconhecida oficialmente em 1540, a Companhia de Jesus teve na evangelização seu ideal, desenvolvido na ideia de apostolado pelo ensino. A fórmula do Instituo não deixou margem para dúvida:

Qualquer um que na nossa Companhia, que desejamos seja assinalada com o nome de Jesus, quiser militar como soldado de Deus, debaixo da bandeira da cruz, e servir ao único Senhor e ao Romano Pontífice, vigário seu na terra, depois de fazer voto solene de santidade perpétua, assente consigo mesmo que é membro de uma Companhia, sobretudo fundada para, de um modo principal, procurar o proveito das almas, na vida e doutrina cristã, propagar a fé, pela pública pregação e ministério da palavra de Deus, pelos exercícios espirituais e obras de caridade, e nomeadamente ensinar aos meninos e rudes as verdades do cristianismo, e consolar espiritualmente os fiéis no tribunal da confissão; e trate de ter sempre diante dos olhos primeiro a deus, depois o modo deste seu Instituto, que é como caminho para chegar a ele, e de conseguir por todas as forças este fim, que Deus the propôs, casa um, todavia, na medida da Graça, que o Espírito Santo lhe comunicar, e no grau particular da sua vocação, não suceda que algum se deixe levar de um zelo não regulado pela ciência. (LEITE, 1938, p. 6). 
A prática da missionação e o trabalho pedagógico forjaram as bases estruturadoras da Companhia de Jesus, que viu o seu corpo de membros aumentar em uma escala extraordinária com o passar do tempo. O crescimento da Ordem pode ser percebido no fato de em 1556, após 16 anos de sua fundação, a Companhia contava com 1150 membros, e no intervalo de 20 anos, em 1580, somava mais de 5000 homens. (CASTELNAU-L`ESTOILE, 2006. p. 188.)

Os missionários encontravam-se dispersos no mundo, e não apenas restritos à Europa. Ásia, África e América passaram também a fazer parte do seu campo de atuação sendo lícito afirmar que os jesuítas fizeram parte do "processo colonizador" de regiões ligadas tanto ao Império português, quanto ao espanhol.

Dispersos por várias partes do globo, os jesuítas estiveram em profundo contato com Roma, sobretudo, por conta da identidade forjada na longa duração de sua formação através de estudos intelectuais profundos atrelados a um constante trabalho interno, cujo principal instrumento foi os Exercícios Espirituais. Essa identidade se definiu pelo "modo de fazer ou agir", uma vez que mesmo não sendo idênticos, os jesuítas agiam de modos semelhantes, sempre orientados pela noção de salvação do outro, que, no fundo, implicava em sua própria salvação ${ }^{1}$.

Inserida no contexto reformista, Igreja a Católica marcou presença na América portuguesa por meio de sua associação com a Coroa portuguesa na empreitada colonial, sendo, sem dúvida, a Companhia de Jesus um de seus braços de atuação. Desde 1549, quando padre Manoel da Nóbrega desembarcou em Salvador na companhia do governadorgeral Tomé de Souza, os jesuítas buscaram atuar no mundo colonial, não medindo esforços no sentido de se relacionar e pensar a sociedade, definindo o seu espaço de atuação nela.

Após um momento inicial de afirmação de um imaginário edênico para as terras pouco a pouco ocupadas pelos portugueses, os relatos da vida cotidiana na colônia passaram a denunciar, além da hostilidade do clima e da fauna, o estado de penúria a que estiveram expostos seus moradores. A distância imposta pelo oceano dificultava o acesso aos grandes centros comerciais, obstaculizando a aquisição de bens de consumo. O relato de Nóbrega sobre ter na Bahia encontrado uns "quarenta ou cinquenta moradores" em condições marcadas pela precariedade, não havendo "óleos de ungir, nem para baptisar" é bastante elucidativo quanto a essa questão. (NÓBREGA, 1988, p. 71-75) Somou-se a isso o estado religioso da população colonial e os péssimos exemplos dados pelo próprio clero paroquial,

\footnotetext{
${ }^{1}$ Expressão utilizada por Charlotte Castelnau-L'Estoile para designar o modus operandi dos jesuítas. Ver CASTELNAUL'ESTOILE, Charlotte de. Operários de uma vinha estéril: os jesuítas e a conversão dos índios no Brasil 1580-1620. Tradução Ilka Stern Cohen. Bauru, São Paulo: Edusc, 2006.
} 
envolvido, não raras vezes, em mancebias e atividades pouco ou quase nada condizentes com a atividade religiosa.

De modo semelhante, passado o momento inicial de euforia onde os jesuítas, por não detectarem manifestações religiosas nas populações indígenas, criaram a imagem do "papel branco" onde poderiam introduzir com facilidade a mensagem cristã, o choque cultural com as populações indígenas causou a impressão de que a propagação do cristianismo na América portuguesa seria tarefa árdua. ${ }^{2}$

A cultura indígena mostrava-se tão distante dos modelos compreendidos pela cristandade que beirava o incompreensível. $O$ indígena não poderia ser comparado com os padrões culturais ou corporais já conhecidos e como consequência disso foi-lhes conferida à noção de in-civilização, caracterizada pela animalidade de seus costumes e evidenciada nas práticas de incesto, canibalismo e nudez. O próprio Nóbrega chegou a afirmar que os povos aqui encontrados

não passavam de cães em se comerem, e matarem e são porcos, por vícios, e na maneira de se tratarem, e esta deve ser a razão, por que alguns padres, que do reino vieram, os vejo resfriados, porque vinham cuidando de converter a todo o Brasil em uma hora e vêm-se que não podem converter em um anno por sua rudeza e bestialidade. (NÓBREGA, 1988, p. 320)

Além disso, a vida cotidiana da população colonial, sobretudo nos primeiros séculos, se caracterizou pela tríade mobilidade, instabilidade e dispersão. A situação de isolamento apareceu com bastante nitidez nas imagens dos pequenos núcleos populacionais contrastando em profundidade com a imensidão do território. Nesse sentido, os colonos

foram aos poucos incorporando o território da América portuguesa ao âmbito do Império: mundo sempre em movimento onde as hierarquias sociais se sobrepunham com maior flexibilidade e rapidez; onde os limites geográficos foram, até meados do século XVIII, fluidos e indefinidos; onde os homens inventavam arranjos familiares e relações interpessoais ao sabor de circunstâncias e contingências; onde aldeias e vilarejos se erguiam de um dia para o outro, nada garantindo que durassem mais do que alguns anos ou que crescessem com a feição ou o ritmo das aglomerações urbanas de além-mar. (SOUZA, 1997, p. 42)

\footnotetext{
2 Sobre a noção de papel branco ver Mary Del Priore, "O papel branco, a infância e os jesuítas na Colônia". In PRIORE, Mary Del (org.). História das crianças no Brasil. São Paulo: Contexto, 1997. p. 10-27.
} 
Tendo em vista todos esses elementos, a fixação jesuíta na colônia seguiu o modelo europeu de fundação de Colégios, deixando em evidência a relevância do projeto educacional no seio da Ordem. Mas além destes, outras modalidades de estabelecimento como as residências e as aldeias de evangelização também foram fundamentais para o estabelecimento jesuíta na colônia.

Responsáveis pelo ensino das primeiras letras - ler, escrever e contar -, os colégios tiveram por função também o ensino dos estudos médios - latim, retórica, humanidades, poesia -, e do curso de artes, além do curso de teologia para aqueles que se candidatavam ao sacerdócio. (TAVARES, 1995, p. 39)

Os colégios funcionavam como uma casa de jesuítas, especializado no ensino e destinado, em parte, aos estudantes externos à Companhia. No Brasil, ainda no século XVI, foram estabelecidos três colégios: Salvador da Bahia (1553), Olinda (1568) e Rio de Janeiro (1567). De fato, o colégio era o centro da vida jesuíta:

fruto de uma evolução iniciada desde os primeiros anos de existência da Companhia, embora não estivesse no projeto original do fundador. Inácio havia imaginado uma Companhia que não teria outro lugar que não o mundo, uma Companhia essencialmente itinerante, que nada possuiria de próprio. Contudo, uma demanda social muito forte orientou rapidamente a jovem Companhia para as tarefas de ensino, o que acarretou sua fixação em alguns lugares onde foram criados colégios que a Companhia tomou a seu encargo. (CASTELNAU-L`ESTOILE, 2006, p. 51-52)

O colégio da Bahia se destacou como central na América portuguesa, contando com 60 jesuítas nele residindo em 1585, o que se explica não apenas por sua antiguidade, mas, sobretudo, pela importância da capital da colônia. Tal colégio funcionava também como seminário dos jesuítas de toda a colônia, tendo uma casa de provação reservada aos noviços a fim de que vivessem em espaço separado durante seus dois anos de noviciado, além de ser o mais rico de toda a colônia, recebendo três mil ducados do rei de Portugal todo ano. (IDEM) Esses espaços foram dotados também de boticas, espécie de laboratórios, onde eram confeccionados medicamentos, conforme veremos mais adiante.

\section{Doenças e os serviços de saúde}

Em face de um cenário de grande precariedade material, as doenças e os surtos epidêmicos que assolaram as regiões e sua população, tendo em vista o estado de carência 
de profissionais da saúde como médicos, cirurgiões, barbeiros e boticários, bem como de medicamentos e hospitais, se constituiu em um capítulo a parte representante das difíceis condições de vida no mundo colonial.

A isso se somou o fato de que a vida cotidiana na colônia se desenvolveu, principalmente, em áreas rurais onde predominou a precariedade e rusticidade das habitações e o pouco asseio dos quintais, desprovidos de qualquer tipo de sistema de esgoto ou água encanada, e também nos empobrecidos núcleos urbanos que se caracterizaram pela imundice acumulada nas ruas, que cercadas por muros para proteção, confinava e aglomerava a pequena população expondo-a as doenças infectocontagiosas e epidemias. Nesse sentido, a elevação da taxa de mortalidade foi responsável por períodos de fome, contribuindo para a situação de desnutrição população colonial, posto que a falta de mão de obra para o trabalho nas lavouras e engenhos prejudicou não apenas os lucros da empresa colonial, mas também a sobrevivência dos indivíduos.

Epidemias de gripe, surtos de "prioris" (pleuris, espécie de pneumonia), câmaras de sangue (disenteria), doenças sexualmente transmissíveis, como a sífilis e a gonorreia, sarampo (ampollas), febre amarela e varíola (bexigas/doença maligna) foram algumas das doenças que frequentemente assolaram o cotidiano colonial e que além da real possibilidade de morte maciça representavam a possibilidade de desorganização social na colônia.

No levantamento feito por Cristina Gurgel (2010) sobre as doenças e processos de cura no Brasil colonial foi destacado que o surto de varíola, ocorrido em Ilhéus entre os anos de 1562 e 1563 causou extraordinária mortalidade entre os indígenas. A dimensão dessa tragédia chegou ao nosso conhecimento através do registro do jesuíta Leonardo do Valle ao destacar que

[...] seu pecado foi castigado por uma peste tão estranha que por ventura nunca nestas partes houve outra semelhante [...] alguns querem dizer que se pegou da nau em que veio o padre Francisco Viegas, porque comelou nos Ilhéus, onde ela foi aportar [...] a mortandade era tal que havia casa que tinha 120 doentes e a uns faltavam já os paes, a outros os filhos e parentes e, o que pior é, as mães, irmãs e mulheres, que são as que fazem tudo [...] faltando elas não havia quem olhasse os doentes, havia muitas mulheres prenhes que tanto que lhes dava o mal as debilitava de maneira que botavam a crianças [...] e destas prenhes quase nenhuma escapava por toda a terra, nem menos as crianças. [...] Finalmente chegou a coisa a tanto que já não havia quem fizesse as covas e alguns se enterravam arredor das casas e tão mal-enterrados que os tiravam os porcos [...] e o que é mais para doer, que muitos morriam sem confissão e sem batismo, porque era impossível acudirem dois padres a tanta multidão [...] se morriam 12, caíam 
20 [...]. Bem me parece que em cada uma daquelas três aldeias morreria a terceira parte da gente porque só em Nossa Senhora da Assunção haverá dois meses que ouvi dizer que eram mortas 1.080 almas, e com tudo isso diziam os índios que não era nada em comparação da mortalidade que ia pelo sertão adentro [...] (GURGEL, 2010, p. 124)

O relato do jesuíta mostra-se bastante significativo no sentido de ilustrar a percepção acerca das doenças e pestes que assolavam o cotidiano das populações, posto que o conhecimento do corpo humano, estabelecido desde a Antiguidade por Hipócrates e Galeno, exerceu forte influência até boa parte do século XVIII.

Nesse sentido, o corpo humano era compreendido enquanto campo aberto à intromissão de forças externas, estando, desse modo, constantemente sujeito a intervenções tanto do bem, quanto do mal. Assim, a enfermidade foi por diversas vezes entendida como prova da ira de Deus, na medida em que a própria doutrina médica estabelecia uma estreita ligação entre a doença e o ambiente, incorporando conceitos de poluição e impureza na explicação de suas causas, misturando ambientalismo e humores na interpretação das moléstias. Mary Lindemann sinalizou que

as mudanças ambientais, uma condição particular do ar ou da água, um verão especialmente quente ou úmido, ou uma desfavorável conjunção dos planetas, por exemplo, podia influenciar negativamente a hidráulica interna do corpo, com previsíveis resultados perniciosos. (LINDEMANN, 2002, p. 9)

Havia uma imensa dificuldade em discernir aquilo que se passava internamente no corpo, sendo, portanto, a linguagem da anatomia carregada de significados. 0 conhecimento de órgãos como o coração, o fígado, o cérebro e o útero não eximia os profissionais da medicina na Época Moderna de recorrer a simpatias na tentativa de restabelecer as relações de um humor com o outro, reforçando, assim, a relação existente entre o microcosmo humano e o macrocosmo do universo, ou seja, a imbricada relação entre medicina e magia.

A concepção da doença como força sobrenatural corroborou para o desenvolvimento de uma medicina, tanto no meio popular quanto erudito, que se por um lado lançava mão da utilização de elementos provenientes dos reinos vegetal, animal e mineral, por outro indicava a utilização de amuletos e rezas. A determinação do governador de São Paulo, Martim Lopes de Lobo Saldanha, quando da epidemia de febre amarela na cidade na 
primeira metade do século XVIII é emblemática, na medida em que ordenou nessa ocasião que

[...] se queimassem ervas perfumadas nos locais onde se encontrassem os atingidos pela peste amarela, e que grande quantidade de bois e carneiros fossem levados de cambulhada, a percorrer ruas, a fim de com isso atraírem, para eles, os bichos, a maldita febre [...] (RIBEIRO, 1997, p. 84)

Nesse cenário, a preocupação com os serviços de saúde é também compreendida enquanto marca da Companhia de Jesus, que não se restringiu à matéria missionária ou educacional nos locais por onde atuou, embora seja impossível negar o valor destes campos no seio da Ordem.

Por meio dos serviços de saúde, os jesuítas desempenharam o papel de enfermeiros e cirurgiões, oferecendo cuidados e tratamentos aos doentes e atuaram como farmacêuticos, manipulando medicamentos através de suas boticas, promovendo, desse modo, auxílio à população colonial diante de um cotidiano marcado pela carência de recursos.

\section{Os jesuítas e o mundo natural}

A experiência do Novo Mundo permitiu aos jesuítas, além do envolvimento com a população nativa, o contato com a exuberante fauna e flora locais, propiciando a utilização de muitos de seus elementos na fabricação de medicamentos. Cabe destacar, porém a existência de um fecundo intercâmbio entre o conhecimento nativo e o europeu, posto que, se por um lado, os missionários lançaram mão de algumas práticas curativas nativas, partindo da utilização de elementos da fauna e flora locais, por outro as uniram ao conhecimento prévio que possuíam da farmacopeia europeia. Esse intercâmbio foi sinalizado por Cristina Gurgel, em obra que tratou não apenas das doenças que afligiram a população colonial, mas, também da formulação de práticas curativas híbridas, ao apontar que

de um lado, ancorados pela filosofia e prática médica europeia, por outro, pela terapêutica indígena, com seu amplo uso da flora nativa, os jesuítas foram os reais iniciadores do exercício de uma medicina híbrida que se tornou marca do Brasil colonial. Alguns religiosos vinham de Portugal, já versados nas artes de curar, mas a maioria aprendeu na prática diária as funções que deveriam ser atribuídas a um físico, cirurgião, barbeiro ou boticário. (GURGEL, 2010, P. 113) 
Ancorados na confluência dos conhecimentos nativo e europeu sobre o mundo natural e seus efeitos terapêuticos, os jesuítas deram início à confecção de cadernos manuscritos a partir de anotações sobre a utilização de certas plantas. A relação composta por Fernão Cardim oferece excelente exemplo dessa prática, encontrando-se nela descrição de árvores e ervas que serviam para medicinas e mezinhas como a igpecacóaya (ipecacuanha), proveitosa no tratamento das câmaras de sangue (disenteria acompanhada de sangramento), a erva santa indicada para "feridas, catarros, além de doenças da cabeça, estômago e asmáticos", a sobaúra apropriada para "chagas velhas, que já não têm outro remédio" e a goembegoaçú, usada no tratamento do "fluxo de sangue de mulheres". (CARDIM, 1980, p. 43)

Em outra passagem da mesma relação, Cardim mencionou a utilização da árvore Cupaigba (Copaíba), de onde se retirava o óleo de copaíba, muito estimado na confecção de medicamentos. A planta foi descrita como

huma figueira commumente muito alta, direita e grossa; tem dentro della muito oleo; para se tirar a cortão pelo meio, onde tem o vento, e ahi tem este oleo em tanta abundancia, que algumas dão hum quarto, e mais de oleo, He muito claro, de côr d'azeite; para feridas He muito estimado, e tira todo sinal. Tambem serve para as cândeas e arde bem; os animais, sentindo sua virtude, se vêm esfregar nellas; ha grande abundancia, a madeira não vale nada. (CARDIM, 1980, p. 37)

Outros jesuítas como José Acosta e José de Anchieta também relataram conhecimento sobre os benefícios da Copaíba. Acosta sinalizou que

o bálsamo é celebrado com razão por seu excelente odor, e muito maior efeito para curar feridas, e outros diversos remédios para enfermidades, que nele se experimentam [...] nos tempos antigos os índios apreciavam em muito o bálsamo, com ele os índios curavam suas feridas e que delas aprenderão os espanhóis... (ACOSTA, 1792, p. 253)

Ao passo em que padre José de Anchieta, em carta dirigida ao Padre Geral Diego Laínes, de São Vicente em 31 de maio de 1560, revelou que

Das árvores, parece digna de menção (embora haja outras que distilam líquidos semelhantes à resina, úteis para remédios), uma que escorre um suco suavíssimo, que querem seja bálsamo. Escorre a princípio como óleo por pequenos orifícios abertos pelo caruncho ou também por incisuras feitas de foices e machados, e depois coalha e parece tomar a forma de 
bálsamo; exala um cheiro não demasiado, mas suavíssimo, e é muitíssimo próprio para curar feridas, de maneira que em pouco tempo nem sinal fica da cicatriz (como dizem estar comprovado pela experiência). (ANCHIETA, 1560, p. 45)

A menção ao uso da Copaíba também aparece no manuscrito Materia medica missionera, de 1710, atribuído ao jesuíta Pedro Montenegro que atuou junto às missões da América meridional ${ }^{3}$. Nesta obra, o autor além de citar a utilização da Copaíba para o tratamento de feridas, fez menção ao fato de ser "hoje muito conhecido e usado por toda a Europa, África e América, com grande estima e preço elevado no Japão e China, conforme estou informando devido às suas admiráveis virtudes". (FLECK, PORTELLO, 2012, p. 1125)

Contudo, esses benefícios também foram constatados por cronistas e viajantes como, por exemplo, Pero de Magalhães de Gândavo em 1576, e Willen Piso em 1648, bem como por moradores da colônia, como o caso de Gabriel Soares de Sousa, em 1587. Cada um a seu modo, sinalizaram que

de certo gênero de árvore a que chamam copaíba, de que se tira bálsamo mui salutífero e proveitoso em extremo para toda sorte de enfermidades, principalmente nas que procedem de frialdade, causa grandes efeitos e tira todas as dores em muito breve espaço, por graves que sejam. Para feridas ou quaisquer outras chagas tem a mesma virtude: logo que com ele as tratam, saram mui depressa, e tira os sinais de maneira que de maravilha se enxerga onde estiverem, e nisto, faz vantagem a todas as outras medicinas. (GÂNDAVO, 2002, p. 86)

os americanos chamam todas as resinas odorosas e gomas pelo nome comum de Copal e que, distinguem por nomes peculiares as suas várias espécies. Assim, também os brasileiros denominam esta árvore, indubitavelmente a principal das resiníferas, Copaliba ou Copaíba. [...] Não somente é eficaz pela admirável virtude de alimpar e consolidar, e para curar quaisquer feridas (mormente dos nervos), ainda no princípio, e as mordeduras de serpentes, e eliminar as cicatrizes, mas por todos os habitantes e por mim foi observado que é de grande utilidade, ministrado internamente. Entretanto, não é de tão suave odor, como quer Maffeu. É quente no segundo grau, grosso e muito pingue e resinoso. [...] É bom untar com ele o peito quando o estômago se acha debilitado, e o ventre, quando afligido por dores de cólicas frias. Algumas gotinhas dadas

\footnotetext{
${ }^{3}$ Ver FLECK, Eliane C. Deckmann. POLETTO, Roberto. Circulação e produção de saberes e práticas científicas na América meridional no século XVIII: uma análise do manuscrito Materia medica missionera de Pedro Montenegro (1710). História, Ciências, Saúde - Manguinhos. Rio de Janeiro, v. 19, n. 4, out.-dez. 2012, p. 11211138.
} 
convenientemente por via oral aumentam as forças às vísceras e restituemIhes o tono: também refreiam os fluxos das mulheres, as diarreias e as gonorreias. Contra estes mesmos males, com bom sucesso, é injetado no ânus por meio de clisteres, no pênis, por meio de uma seringa com água de tanchagem açucarada, ou dissolvido com óleo de rosas. (PISO, 1648, p. 270272)

De tão santa árvore como a do bálsamo merece ser companheira e vizinha a que chamam copaíba que é árvore grande cuja madeira não é muito dura, e tem a cor pardaça; e faz-se dela tabuado; a qual não dá fruto que se coma, mas um óleo santíssimo em virtude, o qual é da cor e clareza de azeite sem sal; e antes de se saber de sua virtude servia de noite nas candeias. Para se tirar esse óleo das árvores Ihes dão um talho com um machado acima do pé, até que lhe chagam à veia, e como lhe chegam corre este óleo em fio, e lança tanta quantidade cada árvore que há algumas que dão duas botijas cheias, que tem cada uma quatro canadas. Este óleo tem muito bom cheiro, e é excelente para curar feridas frescas, e as que levam pontos de primeira curam, soldam se as queimam com ele, e as estocadas ou feridas que não levam pontos se curam com ele, sem outras mezinhas; com o qual se cria a carne até encourar, e não deixa criar nehuma corrupção nem matéria. Para frialdades, dores de barriga e pontadas de frio é este óleo santíssimo, e é tão sutil que se vai de todas as vasilhas, se não são vidradas; e algumas pessoas querem afirmar que até o no vidro míngua; e quem se untar com este óleo há de se guardar do ar, porque é prejudicial. (SOUSA, 1587, p. 202-203)

Pesquisas recentes apontam o efeito positivo da Copaíba para diversas aplicações farmacológicas, como, por exemplo, antiblenorrágico, anti-inflamatório, anti-gonorréico, antisséptico, cistite, estimulante, incontinência urinária, sífilis, antiasmático, bronquite, expectorante, inflamações de garganta, hemoptise, pneumonia, sinusite, dermatite, eczema, psoríase, cicatrizante de feridas e úlceras, cicatrizante intra-uterino, afrodisíaco, anti-tetânico (principalmente em recém-nascidos), anti-tetânico (contra o bacilo do tétano e nas convulsões), anti-reumático, anti-herpético, anti-cancerígeno, anti-tumoral (tumores de próstata), leishmaniose, leucorréia, contra paralisia, dores de cabeça e picada de cobra, conforme destacado por Veiga Jr. e Pinto (2002), o que corrobora o sucesso do "bálsamo dos jesuítas".

É importante destacar que além de cadernos manuscritos confeccionados pelos jesuítas, era levada para espaços apropriados, como quintais e campos, quantidade razoável de espécies nativas e de outros lugares do mundo, o que permitiu a exploração do potencial curativo de cada planta, bem como a utilização de grande variedade destas na fabricação de medicamentos. 
O tipo de relação estabelecida entre homem e natureza, característica da Época Moderna, colocada como desafio para os homens do Renascimento, se definiu através de práticas que visavam estabelecer um domínio e utilização da natureza e, nesse sentido, a preocupação dos jesuítas com o conhecimento do mundo natural aparece como grande exemplo desse período.

Serafim Leite, responsável pela escrita oficial da história da Companhia de Jesus, sinalizou que

a necessidade local obrigou pois os jesuítas a terem abundante provisão de medicamentos; e também logo a procurarem os que a terra podia dar, com as suas plantas medicinais, que começaram a estudar e a utilizar em receitas próprias, como as do Irmão Manuel Tristão de que Purchas dá notícia em 1625. Destes remédios e tisanias, iniciadas no século XVI, se foi pouco e pouco ampliando a preparação de outros, com ingredientes europeus e da terra, até se estabelecer a farmacopéia brasileira. (LEITE, 1953, p. 86)

Contudo, é necessário chamar atenção para o fato de que os jesuítas, enquanto homens inseridos no contexto de experimentação do mundo natural, não podem ter suas ações simplificadas no sentido de que sua atuação se desenvolveu unicamente em função das necessidades e circunstâncias.

\section{Os medicamentos jesuítas}

Especificamente no que remete à questão da produção de medicamentos, a atuação da Ordem pode ser compreendida dentro do quadro das prioridades. O manuscrito de 1766, intitulado Coleç̧ão de várias receitas e segredos particulares da nossa Companhia de Portugal, da Índia, de Macau e do Brasil. Compostas e experimentadas pelos melhores médicos e boticários mais celebres que tem havido nestas Partes. Aumentada com alguns índices e notícias muito curiosas e necessárias para a boa direção e acerto contra as enfermidades oferece excelente exemplo disso ${ }^{4}$.

\footnotetext{
${ }^{4}$ Colecção de várias receitas e segredos particulares da nossa Companhia de Portugal, da Índia, de Macau e do Brasil. Compostas e experimentadas pelos melhores médicos e boticários mais celebres que tem havido nestas Partes. Aumentada com alguns índices e notícias muito curiosas e necessárias para a boa direção e acerto contra as enfermidades, Autor desconhecido, 1766.
} 
A obra de autor incerto apresenta um panorama das moléstias mais frequentes que assolavam o cotidiano das populações, como também suas formas de tratamento, a partir da reunião de 260 receitas de medicamentos confeccionados nas boticas que a Ordem mantinha espalhadas por áreas coloniais do Império português.

Do número total de receitas destacam-se 47 medicamentos produzidos nas boticas da América portuguesa, sendo, respectivamente, 38 do Colégio da Bahia, 7 do Colégio do Recife e 2 do Colégio do Rio de Janeiro, somam-se ainda a esse número outras 15 receitas onde não aparece o nome da botica que os produziu, mas contêm o nome do jesuíta que a criou e que a época se encontrava na colônia, perfazendo, portanto, um total de 62 medicamentos provenientes apenas da América portuguesa.

Esses medicamentos destinavam-se, preferencialmente, para a terapêutica das doenças de pele, anemia e sífilis. Contudo, foram confeccionados medicamentos para uma variada gama de enfermidades e com diversos efeitos, conforme a tabela:

Tabela 1: MEDICAMENTOS JESUÍTAS

ENFERMIDADES

DO PEITO

CORAÇÃO

ESTÔMAGO

CÓLICAS

DISENTERIAS

VARÍOLOA

REUMATISMO
EFEITO

VOMITÓRIO

PURGANTE

FEBRES

ENFERMIDADES DAS

SENHORAS

CHAGAS E FERIDAS

VERMES INTESTINAIS

TUMORES DUROS 


\begin{tabular}{cc}
\hline GOTA & APOPLEXIAS \\
HIDROPSIA & PARALISIA \\
EPILEPSIA & HISTERISMO \\
ESCORBUTO & VERRUGAS E CANCROS \\
NÃO MALIGNOS \\
INSÔNIA \\
MORDEDURA DE \\
COBRA
\end{tabular}

Fonte: LEITE (1956)

Medicamentos como triagas, pós, unguentos e xaropes, eram preparados e guardados nas boticas que funcionaram como uma espécie de oficina ou laboratório e estavam localizadas em dependências especiais dos colégios jesuítas, próximas as enfermarias.

Voltadas para o atendimento dos serviços de saúde essas boticas se constituíam em um dos poucos recursos para a população colonial, uma vez que os medicamentos se encontravam disponibilizados de forma gratuita ao público em geral, com exceção para os que possuíam melhores condições financeiras e poderiam pagar. Nesse caso, a renda era revertida para a botica do próprio colégio, fato indicativo de que houve a preocupação com o constante provimento desses espaços com tudo o que fosse necessário para o seu bom funcionamento.

A preocupação com esse tipo de estabelecimento remonta ao momento de fundação da Ordem, quando se estabeleceu sua existência nos colégios jesuítas, conforme apontou Serafim Leite:

Além das duas modalidades de enfermeiros e cirurgiões da Companhia, havia as Boticas. Existiam em todos os grandes Colégios da Europa, em Portugal e fora dele, e se autorizaram logo com o exemplo de S. Inácio em Roma. A enfermaria de Roma estabeleceu-se em 1555 numa casa comprada ao pé da Torre Rossa. Tratava os doentes o Padre Baltasar de Torres, que era médico; e precedeu todos os farmacêuticos da Companhia, ao menos em Roma, o Irmão Luís Quaresma (Primus pharmacopolae 
officio) português, que chegara àquela cidade com Bernardo de Cangoxima, primeiro japonês, que os portugueses trouxeram à Europa e veio a falecer em Coimbra, religioso da Companhia. (LEITE, 1956, p. 7)

Na América portuguesa é provável que existissem boticas em todos os colégios jesuítas, que eram num total de 17 quando do momento da expulsão dos inacianos em 1759, mas sabe-se, com certeza, das boticas dos colégios da Bahia, Rio de Janeiro, Recife, São Paulo, Maranhão e Pará. (LEITE, 2013, p. 72)

Das informações sobre esses espaços sabemos que se encontravam paramentados com uma série de instrumentos, conforme é possível perceber pela descrição da botica do Colégio do Maranhão, que mesmo não sendo uma das maiores se encontrou:

\begin{abstract}
tres fornalhas, uma estufa com os trastes seguintes: hum alambique de cobre estanhado, dois alambiques de barro vidrado, 5 tachos de arame, um almofariz de 2 arrobas com sua mão de ferro, e outro de 12 libras com sua mão, mais 2 pequenos, tinha mais quatro alambiques de mármore com mãos de pau, mais 2 de marfim pequenos, 6 tamizes com suas tampas de couro, 4 sedaços. Tinha mais 2 almarios grandes e hum bufete grande com 4 gavetas; 2 pares de balanças pequenas, mais duas que eram ordinárias, uma de arame, outra de folha. [...] Tinha mais $\mathbf{3 0}$ tomos de Medicina e Botica, um candieiro de arame, 6 espatulas de arame, huma imprensa, 2 bacias de arame, 2 escumadeiras de arame. Ficou mais em casa do cirurgião Manuel de Sousa $30 \$ 000$ reis em remédios, 5 tomos de Medicina, um alambique de cobre estanhado, 2 alambiques de barro vidrado. (LEITE, 1953, p. 92)
\end{abstract}

Como é possível apreender da leitura da lista de instrumentos encontrados nessa botica, havia a disposição dos boticários além de equipamentos variados uma biblioteca privativa e especializada, que se diferenciava da biblioteca geral do Colégio. No inventário de 1760, também do Colégio do Maranhão consta que em sua botica havia "mais [de] 400 [vasos de barro], todos com os remédios necessários para aquela terra, os quais importariam $400 \$ 000$ reis". (LEITE, 1953, p. 52) Dentre as obras disponíveis para consulta destacavam-se "as de Curvo Semedo como Observações, Atalaya e Polianteia (1680); e de Ferreira, Luz da Cirurgia; Luz da Medicina; e a Pharmacopeia Lusitana". (IDEM)

Sobre a botica do Colégio da Bahia sabe-se que "era ampla, ao rés do chão (Terreiro de Jesus), no lugar precisamente onde é hoje a entrada da Faculdade de Medicina da Universidade da Bahia". (LEITE, 1956, p. 14) Já o manuscrito do catálogo do Colégio jesuítico de Santo Alexandre, localizado em Belém do Grão-Pará, trouxe a notícia de que sua botica achava-se junto com a rouparia, por falta de lugar, e que neste local se encontravam além 
de caixas e baús, "bacias para lavar os pés e sangrias, almofariz, alambiques, estantes antigas, com vidros, vasos, bocetos e balança; e alguns medicamentos antigos não deste ano [1720]". (MARTINS, 2009, p. 197-198)

Existe ainda referência a uma farmácia flutuante, mais conhecida como "Botica do Mar, responsável pelo abastecimento dos lugares da costa, desde o Maranhão a Belém do Pará", mas informações sobre a mesmo não foram encontradas. (LEITE, 1956, p. 16)

Além de possuírem um receituário particular em suas boticas, os jesuítas lançavam mão de uma descrição detalhada que continha a discriminação dos ingredientes utilizados, seu peso, tendo por base a libra medicinal de 12 onças, seguindo-se dos métodos de laboratório para a obtenção de determinados produtos químicos, como por exemplo, o Nitrato de Prata $\left(\mathrm{AgNO}_{3}\right)$, chamado à época de "Pedra Infernal" e utilizado por cirurgiões em processos de cauterização. Destaca-se, também, como um dos medicamentos mais famosos a Triaga Brasílica, espécie de garrafada composta de cerca de 77 itens entre raízes, óleos e sais químicos, utilizada com efeito polivalente, inclusive como antídoto e contraveneno. (LEITE, 1953, p. 295-297)

Muitos dos medicamentos jesuítas ganharam o mundo com sua fama, projetando a América portuguesa no cenário internacional de circulação de saberes e contribuindo para reforçar a rede de Colégios jesuítas espalhados pelo mundo. Nesse sentido, coube também aos jesuítas papel importante na difusão, estímulo e circulação de produtos, até aquele momento, desconhecidos no Velho Mundo.

Ao utilizar produtos naturais próprios das Américas, os jesuítas popularizaram as virtudes curativas de plantas como a erva caraguatá: "espécie, à vista aprazível, mas cheia de préstimos para a vida humana [...] florida tem várias e notáveis espécies. Uma delas é a verdadeira erva babosa medicinal, conhecida, de que usam nossas boticas". (VASCONCELOS, 1977, p. 148) Essa descrição presente na obra de Simão de Vasconcelos fornece excelente exemplo e referência de veículo de divulgação dos tipos de drogas e simples do Novo Mundo. Nesse sentido, Bruno Martins B. Leite (2013) assinalou que:

nas receitas das boticas de Portugal, como aquelas do Colégio de Santo Antão e da Casa de São Roque, e naquelas das boticas do oriente, como aquela do Colégio de Macau, encontravam-se menções a diversas plantas brasileiras. Ali, os boticários conheciam as suas virtudes e empregavam-nas na confecção dos medicamentos. Donde se infere que eram levadas àquelas partes muitas plantas nativas do Brasil. (LEITE, 2013, p. 86) 
Esse intercâmbio de conhecimento botânico entre as diversas boticas jesuítas coloca em evidência a existência de uma rede de circulação de informações fomentada pela Companhia e permite concluir que sempre houve uma preocupação com essa questão científica. Temos ainda a notícia de que nas receitas de boticas jesuítas em Portugal e no Oriente havia constante menção a utilização de diversas plantas encontradas na América portuguesa como a quina, o bálsamo do Brasil ou copaíba e a almécega do Brasil. (LEITE, 2013, p. 86)

É ainda necessário destacar que o intercâmbio do conhecimento botânico foi em grande medida facilitado pelo fato dos jesuítas terem abrigado nas dependências dos colégios, como a casa de hóspedes, filósofos e viajantes em trânsito pelas possessões do império português, o que certamente deu oportunidade para conversas, entre outras coisas, sobre medicina e processos de cura.

\section{Conclusão}

Atuando na América portuguesa desde 1549, os jesuítas desempenharam funções outras para além da prática missionária. Tendo nos serviços de saúde uma parte de sua identidade, os mesmos se relacionaram com a realidade que os cercava de modo a unir conhecimentos europeus com elementos e conhecimentos da fauna e flora locais, na busca de responder a um cotidiano marcado por doenças e surtos epidêmicos.

Nesse sentido, não é possível compreender a dinâmica colonial sem levarmos em consideração o conhecimento desenvolvido pelos jesuítas sobre o mundo natural e sua aplicação na medicina moderna no que diz respeito à utilização e manuseio de plantas de potencial curativo.

O desenvolvimento de medicamentos e práticas de cura, através das boticas jesuítas, assinala a necessidade de um olhar cuidadoso para esses espaços, no sentido de destacar sua função social. Mas, também como espaços de divulgação, circulação e compartilhamento de informações e conhecimentos a cerca de uma nova realidade que aos poucos ia sendo desvendada.

\section{REFERÊNCIAS BIBLIOGRÁFICAS:}

ACOSTA, José. História Natural e Moral das Índias. Madrid, 1792. 
ANCHIETA, José de. Cartas - Informações, Fragmentos Históricos e Sermões do Padre Joseph de Anchieta, S. J. (1554-1594). Rio de Janeiro: Civilização Brasileira, 1933.

CARDIM, Fernão. Tratados da terra e gente do Brasil. Belo Horizonte: Itatiaia; São Paulo: Edusp, 1980.

CASTELNAU-L`ESTOILE, Charlotte de. Operários de uma vinha estéril: os jesuítas e a conversão dos índios no Brasil 1580-1620. Tradução Ilka Stern Cohen. Bauru, São Paulo: Edusc, 2006.

FLECK, Eliane C. Deckmann. POLETTO, Roberto. Circulação e produção de saberes e práticas científicas na América meridional no século XVIII: uma análise do manuscrito Materia medica missionera de Pedro Montenegro (1710). História, Ciências, Saúde - Manguinhos. Rio de Janeiro, v. 19, n. 4, out.-dez. 2012, p. 1121-1138.

GÂNDAVO, Pero de Magalhães de. A primeira história do Brasil: história da provincia de Santa Cruz a que vulgarmente chamamos Brasil: 1576. Rio de Janeiro: Jorge Zahar, 2004.

GURGEL, Cristina. Doenças e curas: o Brasil nos primeiros séculos. São Paulo: Contexto, 2010.

LEITE, Bruno M. B. "Verdes que em vosso tempo se mostrou. Das boticas jesuítas da província do Brasil, séculos XVII-XVIII". In KURY, Lorelai [et al.]. Usos e circulação de plantas no Brasil, séculos XVI a XIX. Rio de Janeiro: Andrea Jakobsson, 2013.

LEITE, Serafim. Artes e Ofícios dos Jesuítas no Brasil (1549 - 1760). Lisboa: Brotéria 1953. Serviços de saúde da Companhia de Jesus no Brasil (1544-1760). Lisboa, Typografia do Porto, 1956.

LINDEMANN, Mary. Medicina e sociedade no início da Europa Moderna. Lisboa:

Replicação, 2002.

MARTINS, Renata Maria de Almeida. O manuscrito do Catálogo do Colégio Jesuítico de Santo Alexandre em Belém do Grão-Pará (1720) da Coleção Lamego do arquivo do Instituto de Estudos Brasileiros da Universidade de São Paulo (IEB-USP). Revista IEB, São Paulo, n. 49, p. 183- 202, mar./set. 2009.

MULLET, Michael. A Contra-Reforma. Lisboa: Gradiva, 1985.

NÓBREGA, Manuel da. Cartas do Brasil. Tradução de João Ribeiro Fernandes. Belo HorizonteSão Paulo: Itatiaia-Edusp, 1988. 
PISO, Willem. História Natural e Médica da Índia Ocidental. Ministério da educação e Cultura/Instituto Nacional do Livro: Rio de Janeiro, 1957.

PRIORE, Mary Del (org.). História das crianças no Brasil. São Paulo: Contexto, 1997.

RIBEIRO, Márcia Moisés. A ciência dos trópicos: a arte médica no Brasil do século XVIII. São Paulo: Hucitec, 1997.

RODRIGUES, Lourival. Anchieta e a medicina. Belo Horizonte: Edições Apollo, 1934.

SOUSA, Gabriel Soares. Tratado descritivo do Brasil em 1587. São Paulo: nacional, 1987.

SOUZA, Laura de Mello e. Formas provisórias de existência: a vida nos caminhos, nas fronteiras e nas fortificações. In: NOVAIS, Fernando A.; SOUZA, Laura de Mello e. (Org.). História da vida privada no Brasil: cotidiano e vida privada na América portuguesa. São Paulo: Companhia das Letras, 1997.

TAVARES, Célia. Entre a cruz e a espada: jesuítas e a América portuguesa. Dissertação de Mestrado. Niterói: UFF, 1995.

VASCONCELOS, Simão de. "Notícias antecedentes, curiosas e necessárias das cousas do Brasil". In Crônica da Companhia de Jesus do Estado do Brasil. Petrópolis: Editora Vozes, $1977,2 \mathrm{v}$.

VEIGA, Vladimir F. Junior. PINTO, Angelo C. O GÊNERO Copaifera L. Química. Nova, Vol. 25, No. 2, 273-286, 2002. 